\title{
De-icing salt contamination of trees in urban environments
}

Street trees and other greenery counteract pollution and

provide important ecosystem services in urban environments. That this valuable vegetation is under stress has emerged issue. Pierre Vollenweider is based at the Swiss Federal Institute for Forest, Snow and Landscape Research which is concerned with the use, development and protection of natural and urba spaces. Together with Gunta Ciolse of the linsthute of Sergio Rasmann University of Neuchâtel, Switzerland, and other colleagues, the team examine the effect of winter application of de-icing salt on trees in temperate and northern cities.

rban vegetation is limited in ecosystem size but still valuable
for the many benefits to humans for the many benefits to hum provided by a natural environment 'ecosystem secosystems, known as 'erbanised world, trees mitigate negative impact of climate extremes, such as summer heat in cities: and help to reduce air and noise pollution, and wa run-off. They host birds, mammals and insects, slowing biodiversity losses and bringing wellbeing rewards of nature in otherwise artificial settings.

But urban environments are as stressful for plants as for other living beings. Cites are warming up at faster rates than are surrounding suburban and rural areas. The soil available for vegetation is often compacted with insufficient moisture a be polluted. In addition, in cities where

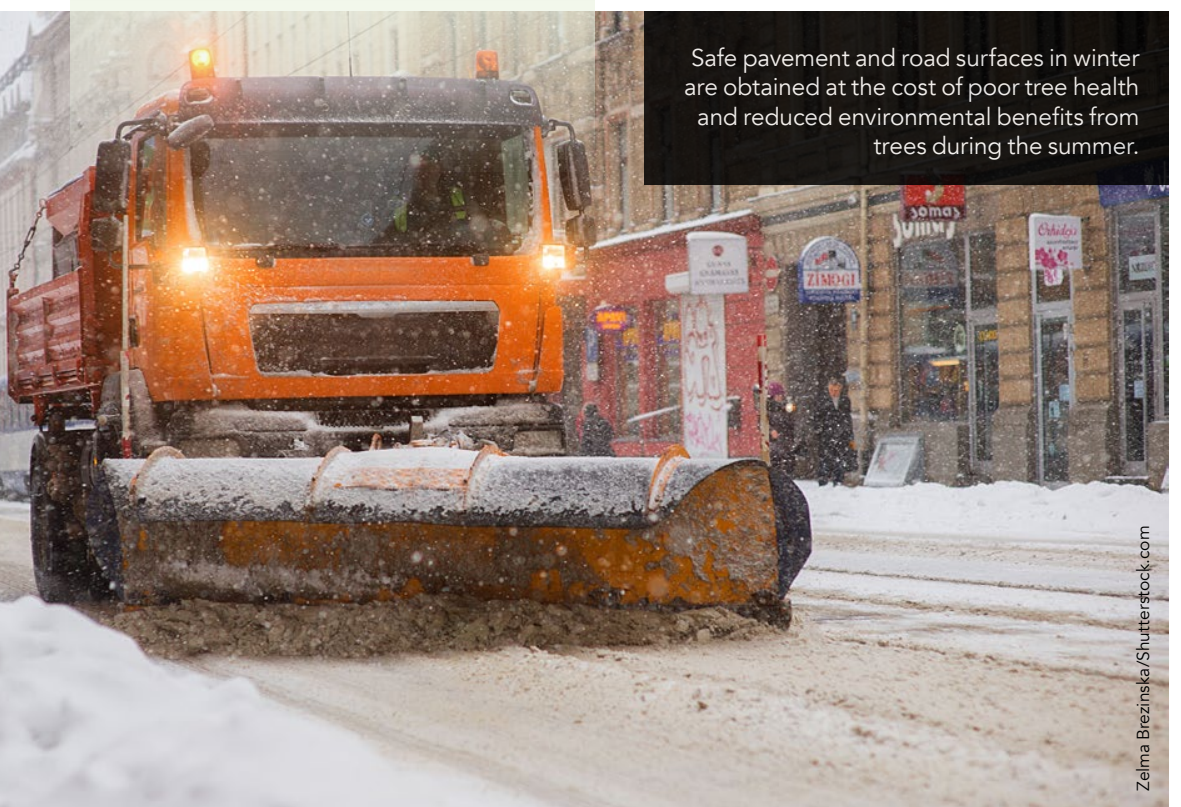

salt is spread to keep surfaces ice-free in street trees, such as the welltal Lime (Tilia spp.), show serious decline.

Safe pavement and road surfaces in winter are obtained at the cost of poor benefits from trees during the summer. Some tree species are more salt-tolerant than others, including ash, poplar or willow. But choice of urban trees also needs to account for other stress factors and important ecosystem services, for example for the cooling of hotter urban climate, for biodiversity maintenance,

and for cultural preferences.

Management of the green infrastructure of cities for the tolerance and resilience of trees should be part of the strategies to counteract clinate change.

ENVIRONMENTAL EFFECTS

\section{OF DE-ICING SALT}

During the winter in countries having

materials are spread for de-icingus

chloride ( $\mathrm{NaCl}$ ) being most com m

With snowmelt, runoff and plowing.

salt ends up in urban soils near roads

and pavements and can spread tens of

metres away. In the soil, its accumulation

destroys soil structure, degrades

organic matter, increases $\mathrm{pH}$, enhances

nitrification level thus promoting leaching

fram

also reduce the availability of important

nutrients to plants.

This winter-applied salt leaches into soils and is taken up in ionic form by surrounding vegetation during the
subsequent growing season. When

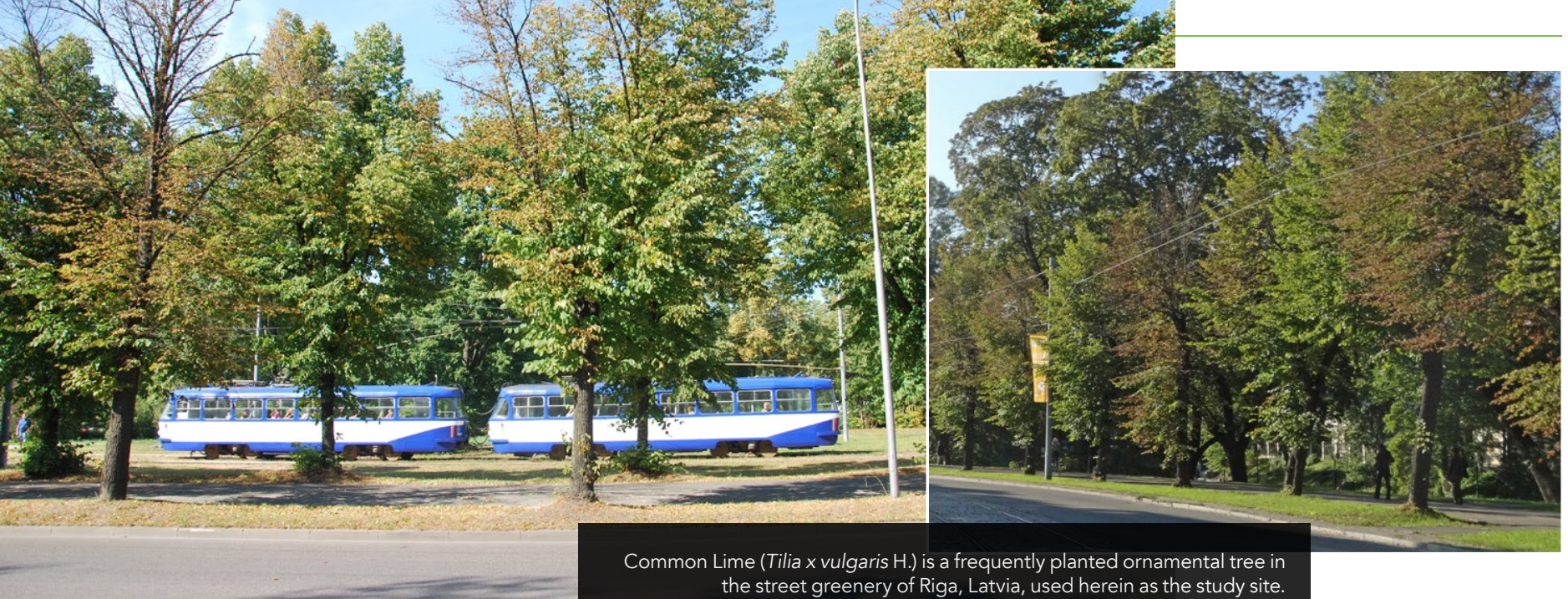

absorbed by roots and translocated into the whole tree, it can cause leaf defoliation, shorterm and crown in the long term. Trees growing salt-contaminted soils are often under osmotic and ionic stress.

Physiological reactions of trees to disturbed osmotic homeostasis include reduced shoot growth, possibly because of root water shortage and decreased leaf photosynthetic activity. Salt-stressed plants modify hormonal signalling,

In cities where salt is spread to keep

reducing root-to-

shoot transport

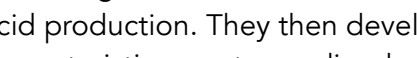
extending to the leaf margin, with ellowing reaching the main veins, before leaf abscission and loss.

Through their research, Čekstere, Vollenweider, Rasmann and colleagues have demonstrated that: urban soil chemistry is altered by salt contamination; sensitive species accumulate salt sodium chloride, as separate $\mathrm{Na}$ and Clions) at over $1 \%$ of foliage dry mass; species and hybrids of the Lime trees they study have tolerance differences; and high arthropod communities in these trees. jume in response to salt accums of salt concentrations in leaves alter Gaining a better understanding of th should help in selecting more resilient and sustainable cultivars to thern Hemisphere.

THE SEARCH FOR SALT-TOLERANT SPECIES OF STREET LIME

Common Lime (Tilia $x$ vulgaris $\mathrm{H}$ ) is a popular frequently planted street tree in Riga, Latvia. However, since the 1960s, decline and mortality has led to increased felling and replacement with young trees. $\mathrm{Na}$ and $\mathrm{Cl}$ ions from

leaves and best retained chlorophyll and water content.

Leaf samples of T. x vulgaris collected from salt uncontaminated and

contaminated street sites in the centre evaluated for leaf necrosis and were for chemical element content. Even on dystrophic soil (having an imbalance of nutrient cations), the trees managed a sustained supply of most key nutrients. ey were able to They were able to nutrient deficiencies (nitrogen, sulphur, boron) or tolerate $\begin{array}{rr}\text { trees show serious decline. } & \begin{array}{r}\text { them (potassium, } \\ \text { manganese), just }\end{array} \\ \text { de-icing salt are found to accumulate as they do for contaminant metals }\end{array}$ $\begin{array}{rr}\text { trees show serious decline. } & \begin{array}{r}\text { them (potassium, } \\ \text { manganese), just }\end{array} \\ \text { de-icing salt are found to accumulate as they do for contaminant metals }\end{array}$ $\begin{array}{ll}\begin{array}{l}\text { de-icing salt are found to accumulate } \\ \text { in leaves, causing necrosis that }\end{array} & \text { as they do for contaminant metals } \\ \text { (iron, copper). Mostly, it was the toxic }\end{array}$ in leaves, causing necrosis that trees. In comparisons with central European species, T. cordata and T platyphyllos, the researchers found that $T$. $x$ vulgaris was the most tolerant. It had the least symptomatic

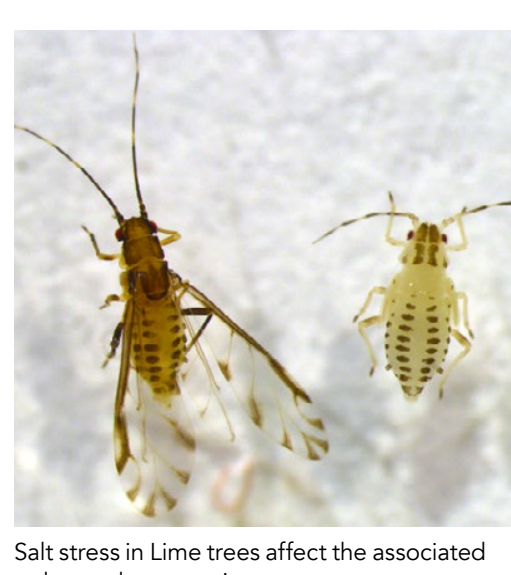
observed foliage damage.

But how does this salt contamination salt ions leached into the ground by melting snow sludge are absorbed by urban tree roots and translocated into the foliage, where they accumulate. Assimilative cells try to remedy this their central vaculising the ions in cell organelles in the surrounding cytoplasm. As a result, and for osmotic reasons, these cells are less able to release water and this hampers leaf gas exchanges, assimilation functions and the cooling of the of Riga, and from a control site at elate quantitatively to structural injury and the mechanisms of toxicity in foliage? During the growing season, 


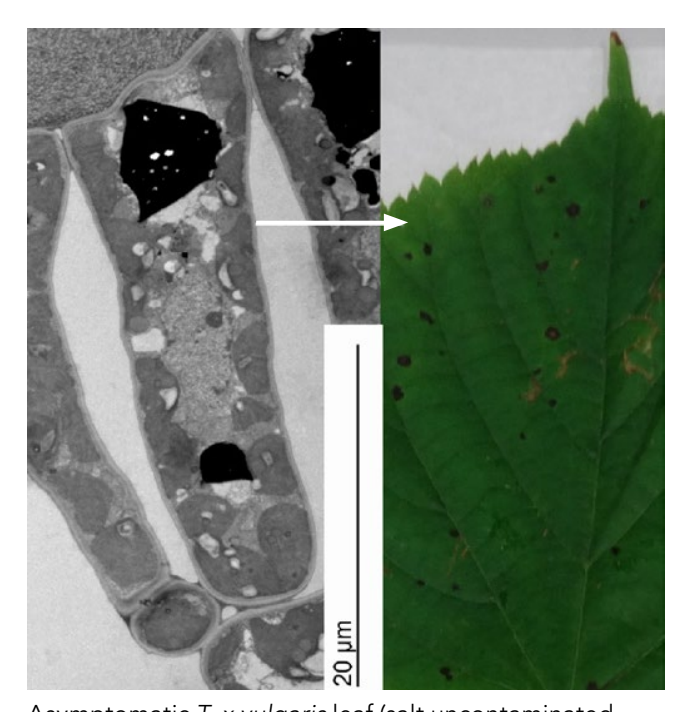
Asymptomatic T. $x$ vulgaris leaf (salt uncontaminated
site, control) and healthy assimilative cell in mesophyll
(transmission electron microscopy image).

The compartmentalisation of salt ions and associated stress defence and havested from urban Lime trees was investigated using light and electron microscopy Anatomical changes in the foliage, increasing in severity from leaf centre to necrotic leaf rim, were found in samples from salt-polluted versus unpolluted sites. In response to salt accumulation, the mesophyll (the part of a leaf between the two thin epidermis layers, containing the cells responsible for photosynthesis) in symptomatic leaves showed an increased turgescence (swelling) and there was evidence of disruption of cell compartments in samples showing the

Given their high mobility, the microlocalisation of $\mathrm{Na}$ and $\mathrm{Cl}$ ion within tissues and cells has been study. Examining the cross-section of samples "vitrified" after undergoing high pressure freezing fixation, the $\mathrm{Na}$ and $\mathrm{Cl}$ ions were clearly shown to be accumulated in the central vacuolar compartments. Not only was the vacuolar ionic content thus raised, but the amounts of essential nutrients such as potassium $(K)$ and calcium were lowered, indicating salt ( $\mathrm{Na}$ and $\mathrm{Cl}$ ) accumulation within leaf cells at the expense of other essential chemical elements. Moreover, the degenerative changes observed in the assimilative cell organelles could be to indirect effects of salt.

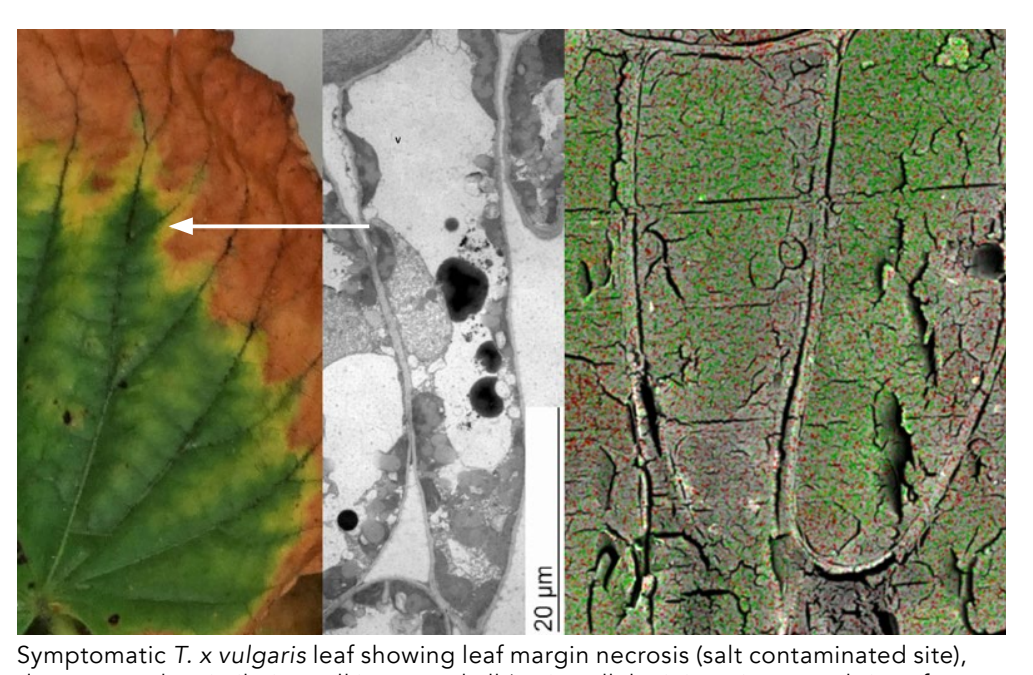

Symptomatic T. X vulgaris leaf showing leaf margin necrosis (salt contaminated site).
degenerated assimilative cell in mesophyll (main cellular injury: increased size of
vacuole and cell, degradation of cell organelles, transmismission electron microscopy vacuole and cell, degradation of cell organelles, transmission electron microscopy
image) and vacuolar allocation of salt contaminants (red: sodium; green: chloride, Image and vacuolar allocation of salt contants
scanning electron cryo-microscopy image).

In summary, sensitivity to salt

In comparing the otherwise similar contamination where it occurs appears uptake strategies leading to highe foliage concentrations for more tolerant species; salt accumulation in stressprone mesophyll: and substitution of $\mathrm{K}$ by $\mathrm{Na}$ in vacuoles. Altogethe these results suggest that salt-induced salt unpolluted and polluted sites, less chlorophyll and probably less nitrogen (N). The diminished arthropod abundance could be partially explained by reduced $N$ and water osmotic effects hinder circadian cell

More vigorous trees-those that are

Salt-induced osmotic effects hinder circadian cell size variation and

evapotranspiration in leaves, indirectly harming photosynthesis.

size variation and evapotranspiration, least stressed_could be the most indirectly harming photosynthesis and city air cooling.

BIODIVERSITY IMPACT OF SALT ACCUMULATION IN LIME

The team also looked at the responses of Eucallipterus tiliae L. aphids in the canopy of Tilia $x$ vulgaris to increased salt levels in foliage. They found that the injuries, anatomical adjustments and ecophysiological responses caused by salt stress in these trees, also affect the associated arthropod community. High salt content could mean that leaves become toxic or unpalatable to herbivores, and this is likely to affect the arthropods. Trees growing on abundance but not lower diversity. from salt-stressed trees containes palatable to herbivores.

Rasmann, Vollenweider and Čekstere conclude that, the impacts of de-icing salts on lime trees have far-reaching effects through the trophic chain, weakening the associated arthropod colerant Lies. Hence, promoting more with a view to healthy trees but also resilient associated biota and, further sustainable urban biodiversity in the street greeneries at mid-latitudes.$$
\text { treet greeneries at mid-latitudes. }
$$$$
\text { 2. }
$$

\section{Research Objectives}

Dr Pierre Vollenweider's research explores mechanistic responses of trees and vascular plants to environmental structure and physiology.

\section{Detail}

\section{Address}

Swiss Federal Institute for Forest, Snow and Landscape Research WSL, Zuercherstrasse 111, 8903 Birmensdort Switzerland

Bio

Dr Pierre Vollenweider holds a PhD in plant anatomy from the University of Lausanne. After a post-doc in forest ecology at the University of Massachusetts, he joined WSL where he currenly leads a microscopylaboratory. He is also anatomy and ecology.

Funding

sciex-NMSch program (grant 14.038)

Basic Research Funding of University of Latvia (for project ZD2015/AZ81.

\section{Collaborators}

Dalinda Bouraoui, Terry Menard, Didzis Elferts, Christophe Rose, Falk Lucas.
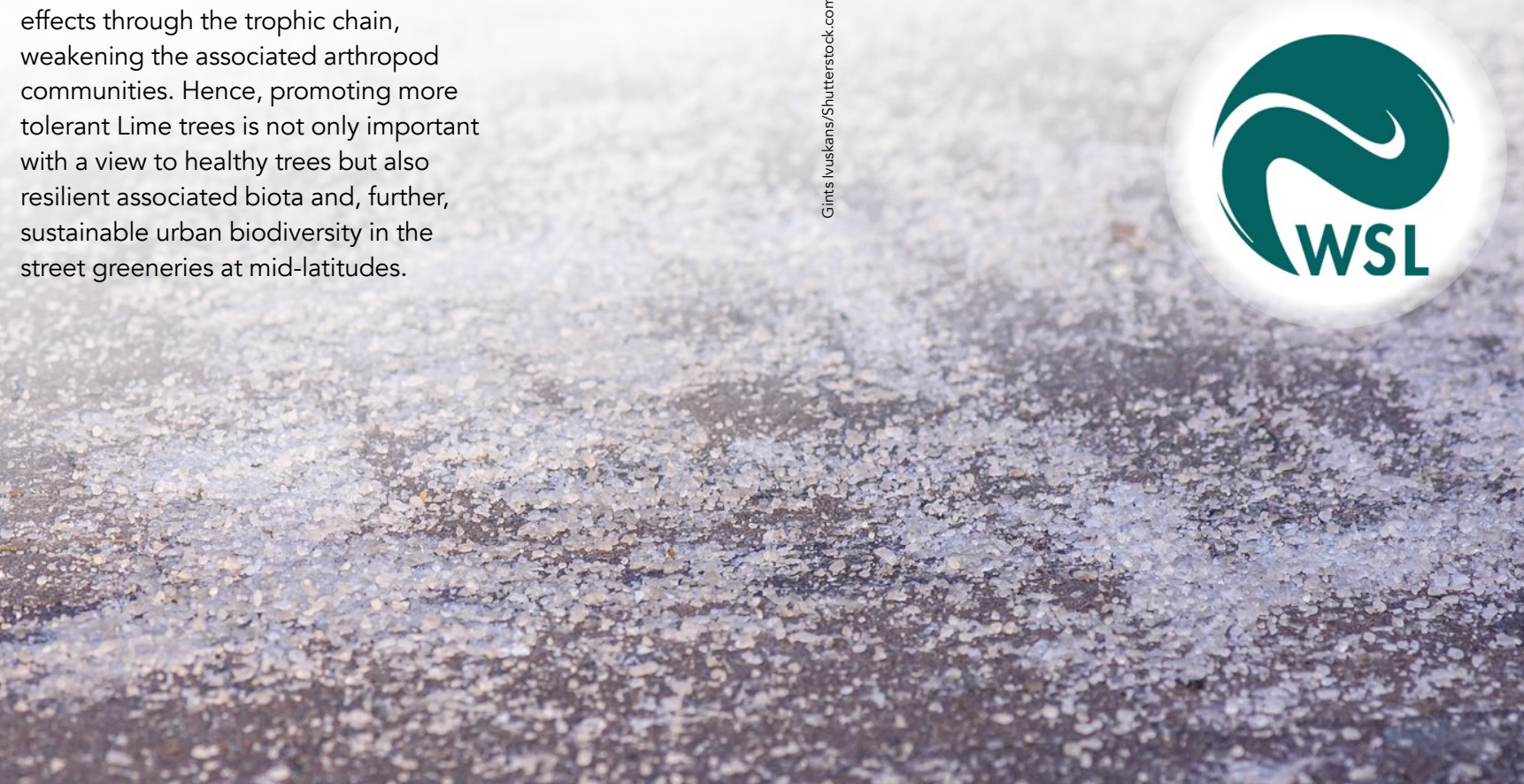

\section{References}

Cekstere, G., et al. (2020) Salt accumulation and effects greenery of Riga, Latvia. Sci. Total Environ. 747, 14092 Bouraoui, D., et al. (2019) De-icing Salt Pollution Affects the Foliar Traits and Arthropods' Biodiversity of Lime
Trees in Riga's Street Greeneries. Front. Ecol. Evol. 7, 282. Cekstere G., et al. (2016) De-icing salt impact on leaves of street trees (Tilia x vulgaris H.) in Riga, Latvia. Acta Biol. Univ

\section{Personal Response}

\section{Do you think that soil salinisation effects on the} could have a role here? What direction will your research now take?

II The fundamental role of micro-organisms regarding tree nutrition has been recognised for a long time
and is mediated by typical associations such as the ectomycorrhizas. Similar to trees in natural ecosystems, the microbial communities in anthropogenic solis - though
the limited biological activity - should play fundamental roles regarding the tolerance and resilience of trees to the deleterious effects of salt contamination on soil
properties. In our research, an indirect indication of their essential contribution was the mostly balanced nutrien soil conditions, knowing otherwise how limiting the poo structured, compacted and debris-rich urban soils can be regarding root growth and soil exploration.

The findings reported here have contributed to mechanistic understanding of tree responses in the
framework of long-term research effort at the University of Latvia on Riga's street greeneries. Further research intitives are foreseen on are applied aspects, species and cultivars to salt pollution. In Switzerland and including salt, our current research has focused on other key stress factors which current impact on anthropized or natural ecosystems directly or indirectly results from elevated tropospheric ozone concentrations, drought events increasing in frequency and severity or soil contamination by metal or other chemical elements. Regarding urban trees and their ecosystem services, performance of street greeneries with a view to urb cooling and the adaptations/adjustments to hourter climate during summer. 